\title{
A case report of congenital cholesteatoma in adult patient mimicking as Bell palsy and proposed follow-up schedule for Bell palsy
}

\author{
Iylia Ajmal Othman ${ }^{1 *}$ (D) Asma Abdullah² ${ }^{2}$ and Noor Dina Hashim²
}

\begin{abstract}
Background: Making the diagnosis of congenital cholesteatoma in adult patients still pose a challenge even among experienced otologists.

Case presentation: We are discussing a case of a young adult who was initially treated as Bell palsy in a different center. Two years later, she presented with marked unilateral hearing loss in addition to her ipsilateral non-resolving facial asymmetry.

Conclusions: Considering the delayed pattern of otological presentation in congenital cholesteatoma, as seen in our case, we proposed monthly follow up in patients diagnosed with Bell palsy for at least 6 months, and those who do not show noticeable recovery after 3 months warrant referral to neurologist or otorhinolaryngologist for further investigations. Contrast-enhanced, high-resolution computed tomography (HRCT) of the temporal bone complemented by magnetic resonance imaging (MRI) supported our diagnosis. Mastoid exploration and complete removal of the disease was imperative.
\end{abstract}

Keywords: Congenital cholesteatoma, Cholesteatoma, Bell palsy, Facial nerve

\section{Background}

A spherical whitish mass medial to an intact tympanic membrane in an adult patient still pose a diagnostic challenge to both novice and experienced otologists. Considering the differing presenting features of congenital cholesteatoma, a heightened suspicion, a thorough clinical examinations, and radiological investigations are mandatory [1]. We are reporting a case of a young lady who presented to us 2 years after she was inaccurately diagnosed and treated as Bell palsy, in another centre. The interesting point of this case is, she is an adult patient in her 20s. The investigations and treatment options will be discussed.

\footnotetext{
* Correspondence: iylia_othman@hotmail.com

'Department of Otorhinolaryngology, Head and Neck Surgery, Kulliyyah of Medicine, International Islamic University Malaysia, Jalan Sultan Ahmad Shah, Bandar Indera Mahkota, 25200 Kuantan, Pahang, Malaysia

Full list of author information is available at the end of the article
}

\section{Case presentation}

A 24-year-old lady presented to our Ear, Nose and Throat (ENT) Clinic with progressively worsening left hearing loss and a non-resolving facial asymmetry, 2 years after she was diagnosed with left Bell palsy at another center. Her left facial asymmetry did not fully recover despite receiving oral corticosteroid and attending facial physiotherapy. She also complained of having intermittent vertigo and non-pulsatile tinnitus. Otoscopic examination revealed a whitish mass medial to the postero-superior quadrant of an intact left tympanic membrane (Fig. 1). Her pure tone assessment demonstrated a left severe conductive hearing loss (Fig. 2). We did not manage to obtain her initial otoscopic findings and hearing assessment, for comparison.

A provisional diagnosis of left congenital cholesteatoma (CC) was made at this point. High-resolution computed tomography (HRCT) of the temporal bone delineated extensive soft tissue density in the Prussak's

\section{Springer Open}

( ) The Author(s). 2021 Open Access This article is licensed under a Creative Commons Attribution 4.0 International License, which permits use, sharing, adaptation, distribution and reproduction in any medium or format, as long as you give appropriate credit to the original author(s) and the source, provide a link to the Creative Commons licence, and indicate if changes were made. The images or other third party material in this article are included in the article's Creative Commons licence, unless indicated otherwise in a credit line to the material. If material is not included in the article's Creative Commons licence and your intended use is not permitted by statutory regulation or exceeds the permitted use, you will need to obtain permission directly from the copyright holder. To view a copy of this licence, visit http://creativecommons.org/licenses/by/4.0/. 


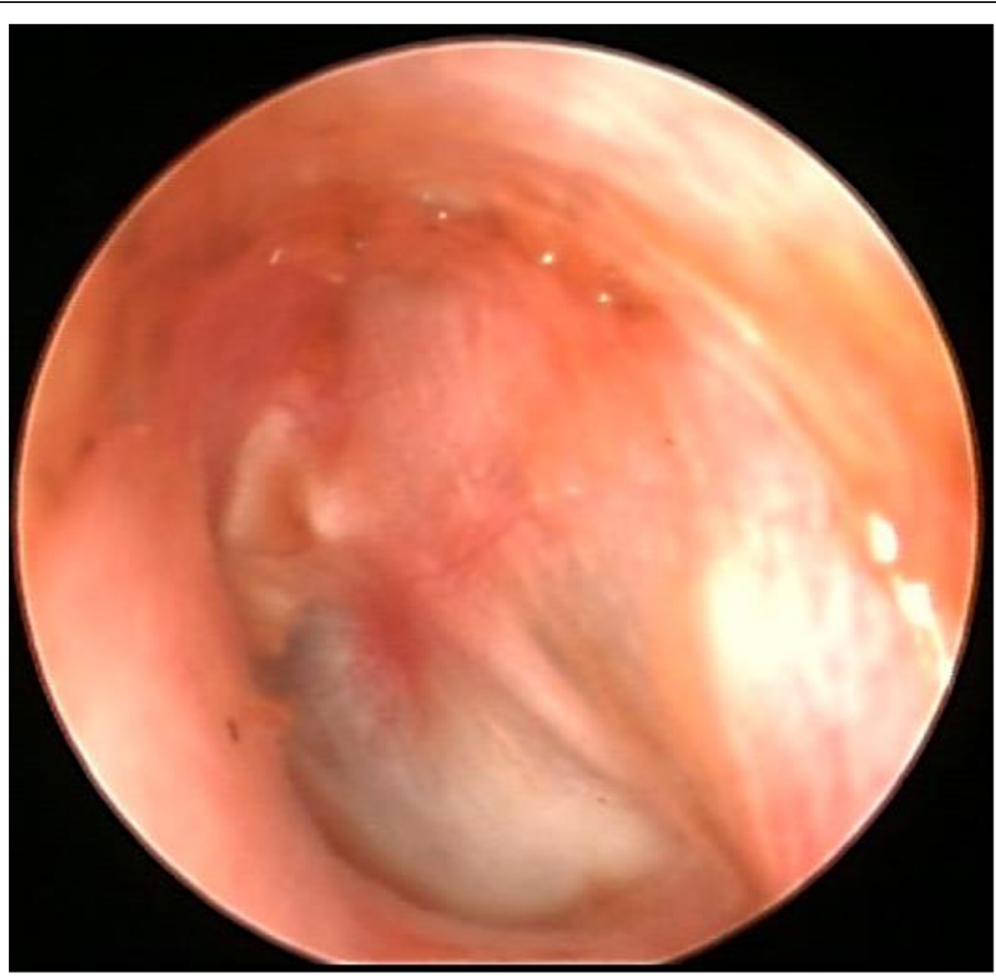

Fig. 1 Bulging left tympanic membrane at the postero-superior quadrant, with presence of a whitish mass medial to it

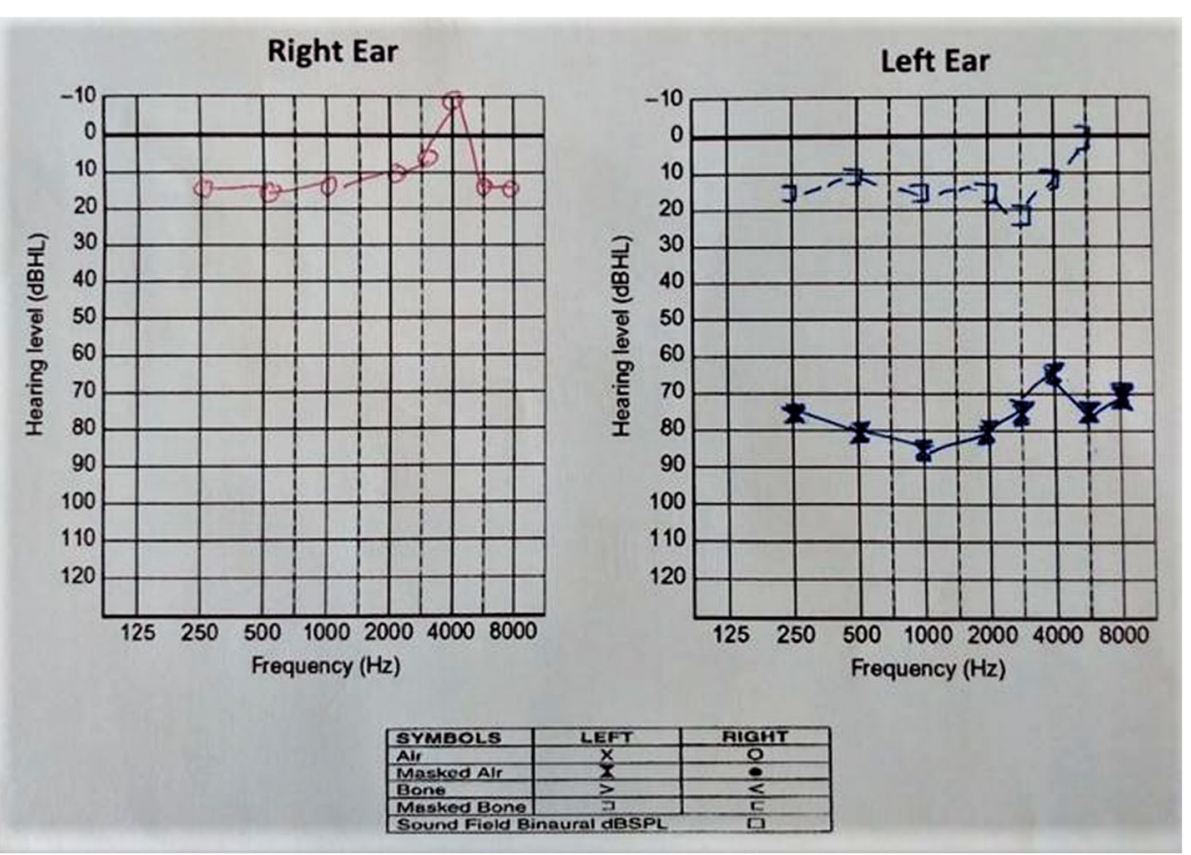

Fig. 2 Left ear showed a severe conductive hearing loss with air-bone gap of 50-60 dBH 
space extending into the left middle ear cavity, involving the mesotympanum and epitympanum causing displacement of normal ossicular configuration (Fig. 3a, b). The geniculate ganglion bony canal as well as the tympanic segment of facial canal appeared dehiscent. Another apparent finding was the left labyrinthine segment of the facial nerve appeared slightly widened; thus, we needed to rule out the possibility of facial nerve schwanomma in view of the patient's initial isolated presentation of facial paralysis.

Magnetic resonance imaging (MRI) showed abnormal signal intensity within the left middle ear cavity which appeared hypointense on T1-weighted, hyperintense on T2-weighted images with minimal peripheral enhancement post-gadolinium (Fig. 3c) coincide with the diagnosis of cholesteatoma. In addition, an abnormal enhancement was observed from the labyrinthine segment, the first genu extending towards the tympanic segment of the left facial nerve. These segments also appeared larger as compared to the right side. The asymmetric enhancement and thickening of the facial nerve segments increased the likelihood of an adjacent inflammatory process with middle ear cholesteatoma. However, the possible differential diagnosis of facial nerve schwanomma still could not be excluded.

She subsequently underwent exploratory mastoidectomy and extended posterior tympanotomy. Epitympanic and mesotympanic areas were occupied by cholesteatoma. Ossicles were eroded. Stapes suprastructure and footplate were absent. The left semicircular canals were all intact. Cholesteatoma was carefully removed in-toto except for the portion overlying the oval window. Tympanic segment of facial canal was dehiscent which might explain the presentation of facial paralysis. Six months after the surgery, the patient's facial asymmetry and hearing level remained the same as pre-operative assessment.

\section{Discussion}

Congenital cholesteatoma $(\mathrm{CC})$ is believed to arise from embryonic epithelial cell rests within the middle ear cleft. They usually present at the average age of 4.5 years
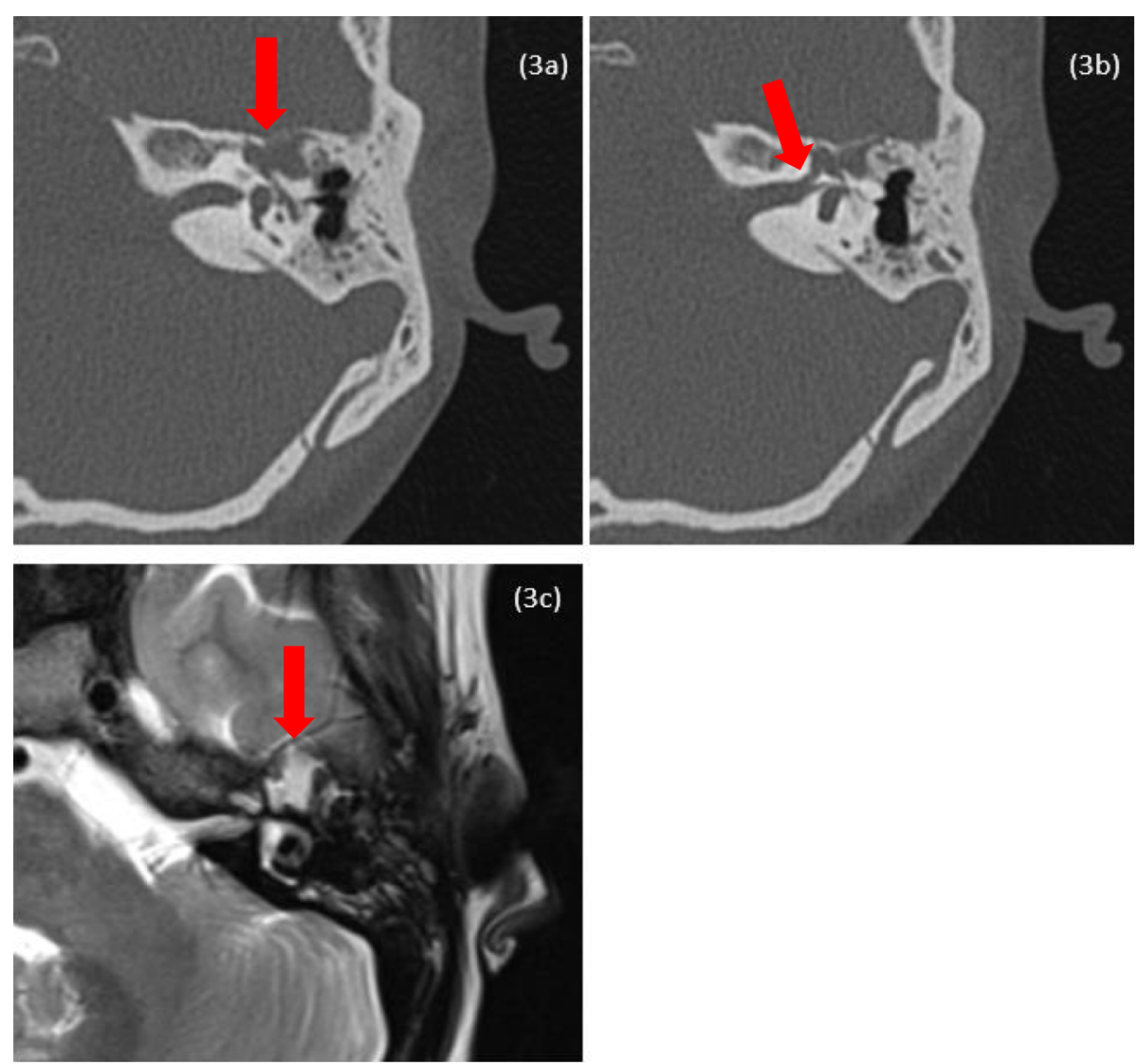

Fig. 3 a Axial cut of HRCT of temporal bone showing soft tissue density within the left middle ear cavity, causing displacement of normal ossicular configuration. The geniculate ganglion bony canal as well as the tympanic segment of facial canal appeared dehiscent. $\mathbf{b}$ The labyrinthine segment of the facial nerve appeared slightly widened. c Axial cut of MRI images depicting an abnormal signal intensity within the left middle ear cavity which appeared hypointense on T1-weighted, hyperintense on T2-weighted with minimal peripheral enhancement postgadolinium suggesting co-existence of cholesterol granuloma 
with 3:1 male preponderance [2]. Interestingly, our case presented in her 20 s.

Schuknecht and Peron stated that CC most commonly occurs medial to the superior quadrant of the tympanic membrane and that it rarely arises in the mastoid cavity [3]. According to a retrospective study by Koltai et al., CC appears to have a predictable trajectory of growth; originating from the antero-superior quadrant, then grow towards the postero-superior quadrant, the attic and eventually into the mastoid [4]. Nonetheless, a systemic review and meta-analysis by Hidaka et al. noted that $\mathrm{CC}$ among Asian populations mostly arise from the postero-superior quadrant, in contrast to findings from western studies, where it is more frequently originated in the antero-superior quadrant [5]. This was similarly seen in our case.

Cholesteatoma often remain asymptomatic and undetected for many years until it has grown into a considerable size or has caused complications [6]. Otoscopic recognition of congenital cholesteatoma is often reliable by experienced eyes but this diagnosis may be unfamiliar to those who are not in ENT or family medicine. Bell palsy being the more generally recognized cause of facial asymmetry often top the list of differential diagnoses especially when no other accompanying symptoms are reported.

Based on a large-scale study done in Copenhagen, 85\% (1448) of those diagnosed with Bell palsy showed improvement within 3 weeks, while the remaining 15\% within 3 to 5 months. Seventy-one percent (1202) of these patients achieved complete recovery within 6 months of onset and no further improvement was observed beyond this period [7]. Based on this knowledge, we proposed a monthly follow up in patients with facial asymmetry for the first 6 months. In fact, those who did not show apparent recovery after 3 months and those with incomplete recovery after 6 months warrant referral to neurologist or otorhinolaryngologist for further evaluations.

Patients with cholesteatoma may not present with apparent hearing loss, although the cholesteatoma has grown into a large size. This is due to the bridging effect of the cholesteatoma in transmitting and conducting sound in the middle ear despite disruption of the ossicular chain $[8,9]$. Patient who presented with sensorineural hearing loss, as seen in our case, indicates inner ear involvement either caused by the toxins secreted or direct invasion. Therefore, patients must be advised to monitor presence of otological symptoms to prevent irreversible complication.

Since the epicenter of our patient's cholesteatoma was in the middle ear, the tympanic segment of facial nerve was most at risk. We postulated that the patient's tympanic segment might be congenitally dehiscent, or the enzymatic activity of the cholesteatoma enhanced the osteoclastic activity, thus causing bony erosions of the facial canal. The same disease process likely has caused pathological dehiscence in the patient's bony labyrinth causing vestibular dysfunction. Apart from facial paralysis, she also presented with occasional giddiness and positional vertigo.

Although the exact clinical findings will be visualized during mastoid explorations, routine radiological assessment prior to mastoid surgery is still deemed necessary [10]. It can facilitate the surgeons regarding surgical approaches and prepare them for suspected complications. A high-quality imaging will be able to show the relevant anatomy, nature and extent of disease, and its complications. These are best appreciated when viewed in axial and coronal sections using $1 \times 1 \mathrm{~mm}$ cutting (HRCT).

HRCT, unfortunately, cannot differentiate between cholesteatoma sac and co-presence of granulation tissue, mucosal edema, or effusion [10], as seen in our case. Although cholesteatoma is said to show a lower attenuation than granulation tissue, the difference is subtle. MRI has shown potential role to differentiate the two. Furthermore, diffusion-weighted (DW) imaging and delayed contrast-enhanced MR has been used to diagnose residual and recurrent cholesteatoma, avoiding the need for second look surgery [11]. This is particularly useful since our patient underwent a canal wall up mastoidectomy.

Nelson et al. discussed surgical approaches to different classification of $\mathrm{CC}$ according to the site(s) of involvement and extension of the disease at the time of diagnosis [12]. In their large series of 119 patients, CC Type 1 (limited to middle ear) were treated successfully via exploratory tympanotomy without the need for second look surgery. Those involving the postero-superior quadrant and the attic (Type 2) required canal wall up mastoidectomy, with or without posterior tympanotomy to control the disease. A second look surgery was performed in $34 \%$ of these patients 9 to 12 months after the first surgery, with or without ossicular reconstruction. For our case, we performed a canal wall up mastoidectomy with extended posterior tympanotomy to clear the disease. The next step of management for her is hearing rehabilitation. She may not benefit from conventional hearing aid given the degree of hearing loss; thus, we will suggest bone conduction hearing device to amplify her hearing. A second look surgery with ossicular reconstruction can also be offered.

A similar case like ours was discussed by Misale et al. One of their subjects was initially treated as Bell palsy which had failed to improve and subsequently presented with symptoms of vertigo and progressive hearing loss [1]. It is highly important to note that an adult patient presenting with unilateral facial paralysis without initial 
otological symptoms must be investigated further especially when it fails to recover within expected duration. Although, there might be little improvement, continuous follow-up, counselling and further evaluations may lead to a definitive diagnosis.

Similarly, the manifestation of facial nerve schwanomma is often insidious and depends on the site of the nerve involved and the extent of the lesion. It may present as progressively worsening facial paralysis or acute facial weakness mimicking Bell palsy. Patients may present with conductive or sensorineural hearing loss depending on tumour origin and its invasion into the middle and inner ear structures. Facial twitching is the common preceding symptoms of facial nerve schwanomma, which should be explored [13].

\section{Conclusions}

A non-resolving or progressive facial paralysis should raise suspicion among physicians. A detailed clinical, radiological assessments and counselling are necessary to rule out an unsafe ear and to avoid complications. Early contrast-enhanced HRCT will expedite the final diagnosis and complete removal of $\mathrm{CC}$ is indicated.

\section{Abbreviations}

CC: Congenital cholesteatoma; HRCT: High-resolution computed tomography; MRI: Magnetic resonance imaging; DW: Diffusion weighted

\section{Acknowledgements}

The authors acknowledged that this is an original work except for the citation and quotation in which the sources have been clearly mentioned. There is no conflict of interest and no financial disclosures to report.

\section{Authors' contributions}

$I A O, A A$, and $N D H$ were all involved in the acquisition and interpretation of data for this manuscript. IAO performed literature review and responsible for the drafting and writing of the manuscript. Critical analysis and revision of the manuscript were done by $\mathrm{AA}$ and $\mathrm{NDH}$. All authors have read and approved the manuscript prior to submission.

\section{Funding}

The writing of this manuscript was not funded.

\section{Availability of data and materials}

All data and material of this work are available from the corresponding author on reasonable request.

\section{Declarations}

Ethics approval and consent to participate

Not applicable.

\section{Consent for publication}

Written informed consent for publication was obtained from the case subject.

\section{Competing interests}

All authors declared that we do not have any competing interests.

\section{Author details}

'Department of Otorhinolaryngology, Head and Neck Surgery, Kulliyyah of Medicine, International Islamic University Malaysia, Jalan Sultan Ahmad Shah, Bandar Indera Mahkota, 25200 Kuantan, Pahang, Malaysia. ${ }^{2}$ Department of
Otorhinolaryngology, Head and Neck Surgery, Faculty of Medicine, The National University of Malaysia, Selangor, Malaysia.

Received: 28 May 2021 Accepted: 7 August 2021

Published online: 23 August 2021

References

1. Misale P, Lepcha A (2018 Dec 1) Congenital cholesteatoma in adultsinteresting presentations and management. Indian Journal of Otolaryngology and Head \& Neck Surgery 70(4):578-582. https://doi.org/1 0.1007/s12070-018-1362-z

2. Levenson M, Michaels L, Parisier S (1989) Congenital cholesteatomas of the middle ear in children: origin and management. Otolaryngol Clin N Am 22(5):941-954. https://doi.org/10.1016/S0030-6665(20)31369-4

3. Peron DL, Schuknecht HF (1975) Congenital cholesteatoma with other anomalies. Arch Otolaryngol 101(8):498-505. https://doi.org/10.1001/a rchotol.1975.00780370040015

4. Koltai PJ, Nelson M, Castellon RJ, Garabedian EN, Triglia JM, Roman S, Roger $\mathrm{G}$ (2002) The natural history of congenital cholesteatoma. Archives of Otolaryngology-Head \& Neck Surgery 128(7):804

5. Hidaka H, Yamaguchi T, Miyazaki H, Nomura K, Kobayashi T (2013 Jun 1) Congenital cholesteatoma is predominantly found in the posterior-superior quadrant in the Asian population: systematic review and meta-analysis, including our clinical experience. Otology \& Neurotology 34(4):630-638. https://doi.org/10.1097/MAO.0b013e31828dae89

6. Kuo $\mathrm{CL}$, Shiao AS, Yung M, Sakagami M, Sudhoff $\mathrm{H}$, Wang $\mathrm{CH}_{\text {, }} \mathrm{Hsu} \mathrm{CH}$, Lien CF (2015) Updates and knowledge gaps in cholesteatoma research. Biomed Res Int 1:2015

7. Peitersen E (2002) Bell palsy: the spontaneous course of 2,500 peripheral facial nerve palsies of different etiologies. Acta Otolaryngol 122(7):4-30. https://doi.org/10.1080/000164802760370736

8. Albera R, Canale A, Piumetto E, Lacilla M, Dagna F (2012) Ossicular chain lesions in cholesteatoma. Acta Otorhinolaryngol Ital 32(5):309-313

9. Jeng F-C, Tsai M-H, Brown CJ (2003) Relationship of preoperative findings and ossicular discontinuity in chronic otitis media. Otology and Neurotology 24(1):29-32. https://doi.org/10.1097/00129492-20030100000007

10. Watts S, Flood LM, Clifford K (2000 Apr) A systematic approach to interpretation of computed tomography scans prior to surgery of middle ear cholesteatoma. The Journal of Laryngology \& Otology 114(4):248-253. https://doi.org/10.1258/0022215001905454

11. Vaid S, Kamble Y, Vaid N, Bhatti S, Rawat S, Nanivadekar A, Karmarkar S (2013 Dec) Role of magnetic resonance imaging in cholesteatoma: the Indian experience. Indian Journal of Otolaryngology and Head \& Neck Surgery 65(3):485-492. https://doi.org/10.1007/s12070-011-0360-1

12. Nelson M, Roger G, Koltai PJ, Garabedian EN, Triglia JM, Roman S, Castellon RJ, Hammel JP (2002 Jul 1) Congenital cholesteatoma: classification, management, and outcome. Archives of Otolaryngology-Head \& Neck Surgery 128(7):810-814. https://doi.org/10.1001/archotol.128.7.810

13. Kirazli T, Oner K, Bilgen C, Ovül I, Midilli R (2004) Facial nerve neuroma: clinical, diagnostic, and surgical features. Skull Base 14(2):115-120. https:// doi.org/10.1055/s-2004-828707

\section{Publisher's Note}

Springer Nature remains neutral with regard to jurisdictional claims in published maps and institutional affiliations. 